\title{
EDITORIAL
}

\section{Transformaciones del derecho y del Estado, un espacio de reflexión de Novum Jus}

A lo largo de la evolución del Estado moderno, este se ha esforzado por establecer una separación de poderes y un control jurídico que permitan el cumplimiento de los derechos; adicionalmente, a través de la historia de la modernidad se ha presentado un incremento considerable de titularidades, particularmente en el campo de los derechos humanos, derechos que han sido reflejados en el ordenamiento jurídico interno y en los innumerables tratados que en el ámbito del derecho internacional público se han producido, particularmente desde las Naciones Unidas.

Ahora bien, frente a la relación individuo, libertad y poder ejecutivo, el Estado constitucional promueve la necesidad de establecer unos límites al Ejecutivo con el fin de prevenir abusos que se pueden dar en el ejercicio del poder y de evitar la aparición de regímenes totalitarios. Para lograr este propósito se estableció un sistema de garantías y de procedimientos incorporados en las cartas constitucionales. Este sistema de garantías busca robustecer el nuevo modelo de Estado constitucional contemporáneo y proteger a los individuos de eventuales abusos del poder:

Las garantías y los procedimientos formales son precisamente lo que ampara y protege la libertad individual y social, en tanto son un medio de defensa frente a los ataques que se dirigen directamente contra los individuos y los grupos sociales en nombre de contenidos materiales, o de supuestos valores, establecidos o interiorizados como algo absoluto; se revelan pues, como instituciones de la libertad, que tienen poco que ver con el formalismo o incluso el positivismo. La supresión de la libertad en los regímenes totalitarios no comienza nunca con un respeto escrupuloso a las garantías formales y los procedimientos, sino más bien con su quebrantamiento en nombre de un derecho material y prepositivo 
superior, ya sea este el de la "religión verdadera", el de la "comunidad popular de miembros de la misma especie" o el del "proletariado".

El Estado constitucional señala que para el cumplimiento de los derechos individuales y sociales se debe establecer una serie de garantías, las cuales se reflejan en principios y procedimientos que tienen como fin la aplicación de la ley, el reconocimiento explícito de la supremacía de la libertad y el control político para evitar el surgimiento de sistemas arbitrarios. Estos principios están hoy en día presentes en un amplio catálogo de tratados internacionales de derechos humanos y en los marcos constitucionales de los Estados de Occidente que constituyen el modelo garantista o modelo de garantías.

Este modelo se encuentra íntimamente vinculado con el sistema jurídico y político del Estado moderno y, de una u otra manera, ha evolucionado con él, de tal forma que las crisis o las transformaciones del Estado nación han ocasionado cambios del modelo garantista. En términos generales, podemos señalar que el garantismo jurídico consiste en el desarrollo de un sistema de principios, normas e instituciones jurídicas que tienen como función sujetar los poderes públicos a la ley y, con ello, evitar la concentración de poder y el autoritarismo de Estado o los regímenes totalitarios. De esta manera el sistema de garantías crea límites y controles al poder del público.

El sistema de garantías, que hoy en día tiene un valor supremo en el Estado constitucional, tiene antecedentes que se remontan al siglo XIX. En un primer momento, en el periodo decimonónico, se generó dentro del Estado de derecho un sistema de garantías diseñado para tutelar los derechos individuales y la libertad. Este sistema se sustentaba en el principio de legalidad y en el habeas corpus.

Posteriormente, en el marco del Estado social de derecho, se construyó un nuevo sentido de lo jurídico y del papel del Estado, que implicó complementar el principio de legalidad y el habeas corpus con otros instrumentos que posibilitan el cumplimiento de los derechos sociales; en particular, estos nuevos mecanismos están reflejados en temas relacionados con la libertad y protección de asociación.

Por último, en el modelo constitucionalista, el sistema de garantías adquiere su máxima expresión al incorporar en norma constitucional los tratados internacionales de

1 Ernst Wolfgang Böckenförde, Estudios sobre el Estado de derecho y la democracia (Madrid: Editorial Trotta, 2000), 42 . 
derechos humanos, y con ello ampliar el rango de protección y de tutela de derechos y promover la justicia constitucional en los tribunales de justicia, los cuales serán los garantes al momento en el cual un ciudadano accione el sistema de garantías.

Vale la pena profundizar en el principio de legalidad, el primer eslabón del sistema de garantías. El principio de legalidad surge con el Estado moderno y su origen está relacionado con el área penal. Así, este pretendió establecer claramente los límites del Estado en manejo de desviación social o de control social. Por medio de la legalidad se dio al poder la obligación de señalar, mediante la ley, las penas por aplicar en caso de una conducta desviada; de esta forma se pretendió evitar la arbitrariedad del Ejecutivo y del Judicial, ya que bajo el axioma nulla poena et nullum crimen sine lege se sometió al juez a la aplicación de la ley, y al legislador, a la construcción de un ordenamiento jurídico que establece con anticipación los procedimientos y las penas. Así el principio de legalidad establece una separación de los intereses políticos y de las concepciones morales y le da al legislador la función de crear la norma jurídica y a los ciudadanos les garantiza la protección de su libertad.

El principio de legalidad, que en su origen se encontró vinculado al sistema penal —derecho positivo—, se traslada así a un ámbito más amplio ligado a la protección de los derechos individuales y sociales y pasa a ser un elemento constitutivo del Estado de derecho, el cual impone límites formales y límites sustanciales al poder que emana del Estado.

Con el fin de la Segunda Guerra Mundial, a mediados del siglo XX, se promueve una serie de instituciones de corte internacional, la principal de ellas es la Organización de las Naciones Unidas (ONU), creada en 1945, cuyo objetivo es, entre otros, garantizar y tutelar el cumplimiento de los derechos humanos, en particular los derechos civiles y políticos. Posteriormente, en 1968, en el marco de la Conferencia sobre Derechos Humanos en Teherán se incorporan los sociales y culturales como parte de los derechos humanos. Este conjunto de titularidades tanto individuales como sociales hará parte de la agenda del derecho internacional ${ }^{2}$ y del derecho interno en los Estados constitucionales.

En esta etapa del garantismo, un elemento importante es la creación o fortalecimiento de instituciones de ámbito internacional, con sistemas mundiales o regionales de

Para profundizar sobre la agenda internacional particularmente en lo relacionado con el derecho internacional público ver, Balakrishnan Rajagopal, El derecho internacional desde abajo. El desarrollo, los movimientos sociales y la resistencia del Tercer mundo (Bogotá: ILSA, 2005). 
protección de los derechos humanos, como la Corte Penal Internacional, el Tribunal de La Haya, la Corte Interamericana de Derechos Humanos y el Tribunal Europeo, entre otros. Adicionalmente aparecerán, con un importante protagonismo tanto en la esfera nacional como en la internacional, las organizaciones no gubernamentales (ONG). Todos estos nuevos escenarios comparten un lenguaje común que se relaciona con la promoción, la defensa, el cumplimiento de los derechos y con velar por que las garantías se cumplan dentro de los Estados.

Finalmente, si el modelo de Estado constitucional se desarrolla en Europa a finales de la Segunda Guerra Mundial, en el ámbito latinoamericano este modelo tuvo su expresión con las reformas constitucionales realizadas a lo largo de la década de 1990. Para América Latina estas reformas promovieron la incorporación en la constitución de temas éticos y políticos, como igualdad sustancial, dignidad, derechos fundamentales, reconocimiento y diferenciación, principios que transforman el sentido de validez de la norma jurídica y de la constitución al adquirir esta un efecto jurídico vinculante.

En el Estado constitucional, la validez de la norma contemporánea se da no solo por el adecuado desarrollo procedimental para su creación, sino que la norma jurídica debe, además, contar con la adecuación a los principios sustanciales señalados en la constitución y en los tratados internacionales, de tal manera que lo anterior limita al poder legislativo y da un nuevo sentido al positivismo jurídico.

En efecto, el sistema de las normas sobre la producción de normas — habitualmente establecido, en nuestros ordenamientos, con rango constitucional-, no se compone solo de normas formales sobre la competencia y sobre los procedimientos de formación de las leyes. Incluye también normas sustanciales como el principio de igualdad y los derechos fundamentales, que de modo diverso limitan y vincula el poder legislativo excluyendo o imponiéndole determinados contenidos. Así, una norma — por ejemplo, una ley que viola el principio constitucional de igualdad_ por más que tenga existencia formal o vigencia, puede muy bien ser inválida y como tal susceptible de anulación por contraste con una norma sustancial sobre su producción. ${ }^{3}$

El modelo garantista adquirió un enorme peso en todo el ordenamiento jurídico de Occidente. Este dinamismo se dio con posterioridad a la Segunda Guerra Mundial

Luigi Ferrajoli, Derechos y garantías (Madrid: Editorial Trotta, 2002), 21. 
y es el resultado de una compleja composición entre el positivismo jurídico, el derecho constitucional y el derecho internacional de los derechos humanos. El resultado de esta combinación es la constitución de vínculos jurídicos formales y sustanciales nacionales e internacionales en el sistema de legalidad.

En la actualidad, todos los Estados de Occidente tienen en el sistema normativo los principios y los valores construidos a partir del escenario de los derechos humanos, y su resultado se observa recientemente en las reformas constitucionales que a lo largo de la década de 1990 se dieron en América Latina, las cuales ubican a los derechos humanos y al sistema de garantías como elementos centrales de las cartas políticas:

Los derechos fundamentales, precisamente porque están igualmente garantizados para todos y sustraídos a la disponibilidad del mercado y de la política, forman la esfera de lo indecidible y de lo indecidible que no; y actúan como factores no sólo de legitimación sino también y, sobre todo, como factores de deslegitimación de las decisiones y de las no decisiones. ${ }^{4}$

Como resultado de este nuevo sentido de garantismo, los poderes en el Estado constitucional de derecho se encuentran limitados por los principios de los derechos fundamentales, principios que se han sido el resultado de un debate político de corte internacional y que llevaron a la Declaración Universal de Derechos de la ONU (1948) y a los Pactos sobre los Derechos (1966).

La ampliación de titularidades en el marco internacional y nacional ha generado nuevas discusiones sobre los derechos humanos, en particular entre los derechos civiles y políticos con relación a los derechos económicos, sociales y culturales. Alrededor del tema emergen distintas posiciones acerca del grado de relación entre los diferentes pactos de derechos humanos y el nivel de exigibilidad por vía jurídica. Algunos sectores consideran que los derechos civiles y políticos son derechos fundamentales y que esto se refleja en el grado de exigibilidad jurídica, ya que son de obligatorio cumplimiento en todo momento y lugar, y el juez está obligado a hacer cumplir y respetar los derechos fundamentales, mientras que los derechos sociales son de orden prestacional y programático y, por lo tanto, no exigibles por vía jurídica.

Ibid., 24. 
Nos ubicamos en el enfoque de la interdependencia, la indivisibilidad y la universalidad de los derechos, de tal manera que entendemos que los derechos humanos - tanto los civiles y políticos como los económicos y sociales— son derechos fundamentales. Los derechos fundamentales son:

Todos aquellos derechos subjetivos que corresponden universalmente a "todos" los seres humanos en cuando dotados de status de personas, de ciudadanos o de personas con capacidad de obrar, entendiendo por "derecho subjetivo" cualquier expectativa positiva (de prestaciones) o negativa (de no sufrir lesiones) adscrita a un sujeto por una norma jurídica; y por "status" la condición de un sujeto, prevista asimismo por una norma jurídica positiva, como presupuesto de su idoneidad para ser titular de situaciones jurídicas y/o autor de los actos que son ejercicio de estas. ${ }^{5}$

En el actual orden constitucional, las garantías jurisdiccionales tienen como función permitir la exigibilidad de cualquier derecho.

Toda esta dinámica del derecho contemporáneo no se puede comprender desde la pretensión de autonomía del derecho, pues implica un análisis de contexto que integre diversas disciplinas sociales. La revista Novumjus se propone analizar el derecho de acuerdo con esta realidad, y para ello la sociología jurídica y la ciencia política aportan las herramientas conceptuales y metodológicas para comprender las transformaciones del derecho y Estado.

Jorge Enrique Carvajal Martínez

Director

\section{Referencias}

Böckenförde, Ernst Wolfgang. Estudios sobre el Estado de derecho y la democracia. Madrid: Editorial Trotta, 2000.

Ferrajoli, Luigi. Derechos y garantías. Madrid: Editorial Trotta, 2002.

Rajagopal, Balakrishnan. El derecho internacional desde abajo. El desarrollo, los movimientos sociales y la resistencia del Tercer mundo. Bogotá: ILSA, 2005.

Ibid., 3 